3. Drain away the excess staining solution. Lower the slide below the surface of distilled water in a petri dish. Gently agitate the slide until it is quite free from methylene blue, and then raise it out of the petri dish with the sections on it. Drain away most but not all of the water. Place the slide in an oven at about $40^{\circ} \mathrm{C}$. until dry. It is important to dry at this temperature or slightly higher or the sections will be wrinkled. After one hour or even less, the sections will be dry enough for dissolving the wax, differentiating, and counter-staining.

The sections or ribbons may be flattened on water if preferred and treated as paraffin ribbons.

Removal of wax may be done in xylol, which will dissolve the wax without dissolving the methylene blue. It does not dissolve the ethyl cellulose very quickly, however, and a mixed solvent of xylol, ethylene glyeol mono ethyl ether ('Cellosolve'), and ethyl acetate is recommended. Should the sections have been stained progressively to a point at which no further extraction of methylene blue is necessary the following mixture is suitable:

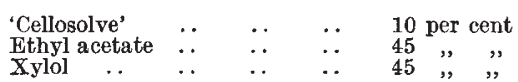

The wax will be removed in about five minutes and the sections may then be transferred to pure xylol, and mounted with balsam in the usual way.

Generally sections are overstained and differentiated in a mixture similar to the above but with a greater proportion of the stain solvent- 'Cellosolve'. In some cases pure 'Cellosolve' alone may be needed to remove the methylene blue from the tissues. Extraction is stopped by placing the slide in the 10 per cent 'Cellosolve' mixture.

Sections can be counter-stained in erythrosin or eosin dissolved to saturation in the following :

\begin{tabular}{|c|c|c|c|}
\hline 'Cello & & & \\
\hline Ethyl acetate & $\ldots$ & . & $\ldots$ \\
\hline$\overline{\mathbf{X} y l o l}$ & $\therefore$ & . & .. \\
\hline
\end{tabular}

This process takes place simultaneously with differentiation of methylene blue or other stain and with the removal of wax. Sections may first of all have part of the wax removed in the 10 per cent 'Cellosolve' mixture, or in pure 'Cellosolve' if heavily overstained with methylene blue, and then may be transferred to the counter-stain. In this the tissue will continue to lose a trace of methylene blue and any remaining wax will be dissolved. When staining is satisfactory the slide is placed in a lower "Cellosolve" mixture (10 per cent or less). This will prevent any further extraction of methylene blue and will also slightly intensify the erythrosin staining. Finally the slide is transferred to pure xylol, and mounted in balsam.

Clean differentiation of both stains and perfect control throughout all operations are the principal advantages of the method. Other stains may be employed, but methylene blue and erythrosin have, up to the present, been the most satisfactory.

To prevent the methylene blue fading the sections should be mounted in 'Sira' (Stafford Allen \& Co., London) and not baked. Such preparations will last for years.

The general outline of the method has been given above. In practice the following solutions are found to cover any combination of wax removal, differentiation of the first stain and application of the counter-stain which may be required:

$\begin{array}{lccccccccc} & & 1 & 2 & 3 & 4 & 5 & 6 & 7 & 8 \\ \text { 'Cellosolve' } & . & - & - & 5 & 10 & 20 & 40 & 80 & 100 \\ \text { E. acetate } & \ldots & - & - & 47 & 45 & 40 & 30 & 10 & - \\ \text { Xylol } & \ldots & 100 & 100 & 48 & 45 & 40 & 30 & 10 & -\end{array}$

No. 5 should have erythrosin to saturation.

The following reagents are not usually supplied by the general chemical supply houses, but may be obtained from the sources given : diethylene glycol distearate (Messrs. A. Boake Roberts, "Ellerslie", Buckhurst Hill, Essex); ricinoleic alcohol (octadecanediol) (Imperial Chemical Industries, Stocktonon-Tees) ; ethyl cellulose, low viscosity (Messrs. J. M. Steel, Kern House, Kingsway, London).

\section{THE BRITISH COUNCIL}

$T$ HE last annual report of the British Council, which covered the year ending March 31, 1944 (see Nature, 155, 58; 1945), well indicated the importance of the work of the Council, not only in the war effort but also for the establishment of cultural relations in times of peace. The Council's work in making British contributions to science better known abroad and promoting contacts between British men of science and those of other countries, particularly since the establishment of its Science Department four years ago, has become so important that the tenth anniversary of the inauguration of the British Council in July 1935 should not be passed unmarked by scientific workers.

The present moment is therefore appropriate to recognize the work of its Science Committee and its Pure Science Panel, of both of which Sir Henry Dale is chairman, as well as its Panels for Medicine, Engineering and Agriculture. One of the earliest activities of the department was the publication of a four-page illustrated newsletter, Monthly Science News, in which accounts of researchare presented in a form intelligible to non-scientific readers. Translated into French, Spanish, Portuguese and Arabic and reprinted in seven different countries, this has now a monthly circulation of 65,000. Compiled in collaboration with learned societies, professional bodies and the scientific and technical Press, Science Comment, a monthly compilation of abstracts and reviews started in 1943, is circulated to universities, libraries, etc., and scientific workers overseas to keep them informed of important publications in the scientific and technical field. A section has recently been added dealing with scientific films. The publication is used by booksellers as a valuable indication of British scientific publications likely to be in demand and in introducing technical and scientific periodicals to a wider overseas public.

Much has been done by the Council to enable British men of science to keep in touch with fellowworkers in other countries in the same field; the exchange of papers and specimens has been maintained and an ever-increasing number of requests for scientific information reaches the Council. Much material for Nature has been transmitted by the British Council. To facilitate the work in France, a scientific adviser has been appointed to the recently opened office in Paris. Scholarships are awarded by the Council to enable promising students to visit the United Kingdom and learn of British methods; since 1939 more than six hundred students have been brought from the Dominions, Colonies and many other countries.

During the War, some three hundred short-leave courses have been arranged at universities, technical 
colleges and other institutions in Britain for about ten thousand members of the Dominions and U.S. Forces, and under the Professional Contacts Scheme a large number of scientific and professional men in the Dominion and Allied Forces have been put into contact with their opposite numbers in Great Britain and with appropriate professional bodies. The secretary of the Engineering Panel, Prof. S. J. Davies, also acts as consultant to the Council; his section seeks to promote a better knowledge of the status and the achievements of British engineering and of the engineering qualifications granted by British universities and the major British engineering institutions.

The Medical Department's British Medical Bulletin is now in its third year, with editions in English, French, Spanish, Portuguese and Turkish, and its reputation is steadily being extended now that a limited number of copies are available by subseription in Britain; a similar arrangement is being developed elsewhere, supplementing the previous restriction to medical editors, teachers, investigators and libraries. On the suggestion of a Swedish professor of medicine, the English edition is reprinted in Stockholm. The present edition exceeds 12,500 copies, and more than three hundred foreign medical periodicals are regularly received in exchange. Requests for copies of papers, bibliographies and general information on medical subjects now form an important part of the work, and this and other services have led to many requests for small supplies of new drugs for research purposes and for new or improved types of medical instruments and apparatus of British manufacture. The Department also acts as an agent for the supply to foreign laboratories of standard bacterial cultures, sera, etc., and has made a start on a programme of medical films, with commentaries in several languages, intended primarily for overseas medical audiences.

The chairman of the Medical Panel is Sir Edward Mellanby; of the Engineering Panel, Sir William Larke; and of the Agricultural Panel, Dr. J. A. Scott-Watson. Mr. J. G. Crowther is secretary of the Science Committee and director of the Department.

Even without taking account of the general educational work of the Council, there can be no mistaking the value of the contribution of scientific collaboration which the British Council has unobtrusively made during the last ten, and especially the last four, years.

\section{SOME BRITISH WORK ON NUTRITION}

$\mathrm{N}$ UTRITION is the theme of vol. 2, Nos. 10 and 11 of the British Medical Bulletin. The issue opens with an article on nutritional seience in medicine by Sir Edward Mellanby. Sir Edward pleads for an international agreement on the optimum composition of bread and other cereal foods which form such a large proportion of the normal diet. The Health Section of the League of Nations has prepared the way for this kind of agreement by working out the international standardization of vitamins and by setting up standards of nutrition in terms of common foods. Discussing bread, Sir Edward says that British men of science consider that it should be made of flour containing as much of the wheat grain as can be physiologically absorbed, that is to say, the whole grain except the outer coarse bran; some North American workers, on the other hand, favour the old type of low-extraction, and white flour with the addition of vitamins known to be present in the wheat grain. The health of the consumer, said Sir Edward, and not the milling or other interests concerned, should control the composition of bread.

This question was raised during a discussion of the nutritional value of bread held by the Nutrition Society last February (see Brit. Med.J., 379, March 17, 1945). The matter was also debated in the House of Lords (see Lancet, 320, March 10, 1945; Brit. Med. J., 393, March 17, 1945). During this debate Lord Horder and others strongly criticized the Government's decision last January to use for the national loaf flour of 80 per cent extraction instead of the flour of 85 per cent extraction adopted in 1942 . Both the medical journals vigorously discussed this national question in leading articles.

If the composition of bread is vitally important as a basic nutritional factor in health and disease, the importance of other factors is revealed by various expert articles in the issue of the British Medical Bulletin under notice. These articles discuss protein metabolism, minerals, nutritional factors in dental disease, the physical, chemical and microbiological determination of vitamins and water metabolism. Dr. S. S. Zilva's article on vitamin C criticizes much of the recent literature about this vitamin. $\mathrm{He}$ concludes that so far there is no convincing evidence that vitamin $\mathrm{C}$ has an influence on any condition other than scurvy. "It is true," he says, "that synthetic $l$-ascorbic acid has its advantages in certain cases of human disease, but this is by no means balanced by the gross and unwarranted abuse of the compound for nutritional purposes." Dr. Magnus Pyke, of the Ministry of Food, records interesting facts about the problems of British war-time food rationing. The review of selected papers on nutrition which follows the main articles provides a valuable compendium of the mcst important literature.

This issue of the British Medical Bulletin could advantageously be read together with reports (Brit. Med.J., 127, Jan. 27, 1945 ; The Lancet, 829, Dec. 30, 1944) of the Nutrition Society's meeting on the nutritional role of the microflora of the intestines, to some aspects of which the work of the Unit of Animal Physiology working at Cambridge has made valuable contributions (see R. A. McAnnally and R. T. Phillipson, Biol. Rev., 19,$41 ; 1944)$. The facts given at this meeting of the Nutrition Society about the biosynthesis of certain vitamins in the bowel will have their influence upon medical practice. The lancet (loc. cit.) reviews, for example, the evidence for the view that the use of sulphonamides may sterilize away the beneficent bacteria which synthesize essential vitamins. The conclusion that we shall have to regard the intestinal flora as part of the individual's constitution is yet another of many recent instances of that consideration of the whole organism plus its environment, which is a fundamental concept of modern biology. If, moreover, it is true that certain vitamins may be synthesized in the intestine, it may be necessary, as the British Medical Journal (191, Feb. 10, 1945) warns us, to reconsider work done on these vitamins with man as the experimental animal. Certainly the work here discussed by this journal suggests that further investigation is required of the view that diets very deficient in vitamin $B$ may quickly cause physical and mental deterioration.

G. Lapage. 